$1-2015$

\title{
Formal and informal academic language socialization of a bilingual child
}

Hyonsuk Cho

University of North Dakota, hyonsuk.cho@UND.edu

How does access to this work benefit you? Let us know!

Follow this and additional works at: https://commons.und.edu/tl-fac

Part of the Linguistics Commons

\section{Recommended Citation}

Hyonsuk Cho. "Formal and informal academic language socialization of a bilingual child" (2015). Teaching \& Learning Faculty Publications. 2.

https://commons.und.edu/tl-fac/2

This Article is brought to you for free and open access by the Department of Teaching and Learning at UND Scholarly Commons. It has been accepted for inclusion in Teaching \& Learning Faculty Publications by an authorized administrator of UND Scholarly Commons. For more information, please contact und.commons@library.und.edu. 


\title{
Formal and informal academic language socialization of a bilingual child
}

Hyonsuk Cho, University of North Dakota

\begin{abstract}
This ethnographic case study examines a bilingual child's academic socialization in both formal and informal academic communities. The study follows a high-achieving, bilingual student in a public US elementary school, who paradoxically is seen as a slow learner in her Korean-American Sunday school. From the academic socialization and community of practice perspectives, 360 contextual, interactional, and interview events gathered from both communities over the course of one year are analyzed. The findings indicate that explicit norms and peer collaboration have a considerable effect on a child's socialization in a formal academic school context, and furthermore, that the lenient, undisciplined environment and diverse language ideologies present in an informal bilingual academic context, such as a church's Sunday school, also considerably influence a child's socialization. This paper discusses how a bilingual child constructs multilingual and multicultural competences and identities through diverse and even conflicting socialization experiences from two different learning contexts.

Keywords: bilingual, multimembership, language socialization, academic socialization, community of practice
\end{abstract}




\section{Introduction}

Academic socialization is the process of learning the norms, values, and appropriate behavior of an academic community (Morita 2009). An academic community can be of two types - formal and informal. A formal academic community can be defined as a credentialed academic context that teaches standardized and structured content and is part of a hierarchical structure such as a school district (e.g., the public school system from kindergarten to university), whereas an informal academic community can be defined as a relatively autonomous, non-credentialed academic context that teaches community related content (e.g., family, neighborhood, library, and religious community; Scheerens 2006). An example of the latter type is a church’s Sunday school where students participate in religiously oriented reading, discussion, reflection, and creation (McMillon and Edwards 2000). Informal academic communities offer students a wide variety of chances to learn.

Children of immigrant families are often engaged in different cultural and linguistic communities. These include school, home, and the heritage language communities such as church and heritage language school. So engaged, they frequently hold multiple memberships and are socialized into each community’s distinct social values and norms. Only a few studies have compared bilingual children’s learning and socialization processes in academic communities outside school to those in formal scholastic contexts (e.g., García-Sánchez 2010; Moore 2006). Tracing socialization in different academic contexts enables a researcher to compare the various educational practices in which students participate and to identify the similar and particular language socialization practices that children with multiple academic memberships might experience (García- Sánchez 2010). 
The present study follows a bilingual girl who has been contradictorily evaluated by her formal and informal academic communities. That is, the bilingual child's Korean- American church’s Sunday schoolteachers considered her to be a slow learner and inarticulate speaker of both English and Korean, whereas her US public schoolteachers regarded her as an advanced student and fluent English speaker who did not even require English as a Second Language (ESL) classes. These contrasting assessments exemplify the divergent experiences and socialization processes a bilingual child experiences across different academic communities. Some people may question why a child's evaluation outside of school matters and why two clearly different contexts should be compared. First, this paper aims not to compare two different environments, but to highlight two distinctive socialization practices that the observed child experiences across linguistically, culturally, and functionally divergent academic contexts as to better understand the bilingual child in both contexts. Observing the experiences and social interactions in one particular context can offer only a partial view of a child's learning capacity and socialization. A multi-sited study like this can help researchers, educators, and parents of bilingual and bicultural children understand a child's language use and social development more comprehensively and extensively. Thus, this study describes the focal child and her peers' socialization processes and learning environments in both a public school and a religious academic context and investigates how these formal and informal educational contexts differ so as to account their contrasting evaluations.

Previous studies on academic socialization have mainly worked with young adults and college students in a single setting (e.g., high school or college; Atkinson 2003; Morita 2009; Pon, Goldstein, and Schecter 2003). Findings from multi-sited studies can deepen our knowledge of children’s academic socialization in different linguistic and cultural contexts. Moreover, they 
can shed light on how the interplay between the multiple memberships in linguistically and culturally diverse educational communities impact bilingual children’s socialization and development.

\section{Theoretical framework}

In analyzing a bilingual child's socialization in formal and informal contexts, this study draws on both academic socialization (Morita 2009) and multimembership of community of practice (Wenger 1998). Following the principle of the theoretical tradition of language socialization, academic socialization is defined as a process of participating in the discursive practices of a given academic community and of becoming a competent member of the academic community (Morita 2009). The main premise of traditional language socialization theory is that novices learn a language to socialize and socialize to use language appropriately; in such fashion they gradually start functioning as competent members of a society (Ochs and Schieffelin 1984, 2012). Ochs and Schieffelin (1984) emphasize that both language ability and sociocultural knowledge are necessary for becoming a competent member of a society. Language socialization theory argues that a person who is a novice in one situation can be an expert in another situation, and it further underscores the agency of novices whose participation is promoted but not determined by experts (Ochs and Schieffelin 2012).

As language socialization research typically employs an ethnographic approach, it gathers multiple cases looking for general patterns on how novices learn language and sociocultural knowledge by being exposed to and participating in language-mediated interactions. The current study focuses on a single bilingual child who regularly participates in two different academic contexts. The study considers how, in becoming a competent member of the community, the child acquires sociocultural knowledge including the norms, values, beliefs, 
and rules of each academic context. The focus of this study is thus, academic socialization - the perspective that specifically highlights socialization in an academic context. Academic socialization analyzes how an individual's socialization is influenced by discursive practices and interactions with various members of his or her academic community (Morita 2009). It also underscores the issue of power from a critical discourse perspective, examining the discourses in which an individual's power struggles and conflicts are represented.

Analyzing different communities of practice in order to understand the relationship between an individual's identity and his or her membership in multiple communities constitutes another aspect of this paper's theoretical approach (Wenger 1998). Wenger (1998) views identity as a nexus of multimembership: 'An identity combines multiple forms of membership through a process of reconciliation across boundaries of practice' (163). Because people belong to more than one community of practice (e.g., work, school, home), people shape different parts of themselves through various forms of participation with different communities of practice. The experience of multimembership generates multiple identities that coexist in a nexus and form one’s identity (Wenger 1998). While much language socialization research has examined how people - mainly children - learn language and behavior that is appropriate within a particular context such as a family, neighborhood, or ethnic cluster, the concept of ‘multimembership' is helpful in relating one’s identity to language socialization between specific contexts. Drawing upon academic socialization, language socialization theory, and the role of multimembership in communities of practices, I study a bilingual child's academic socialization practices across two educational contexts. 


\section{Literature review}

\section{Bilingual children, language, and socialization in formal educational contexts}

Research has shown that in formal educational contexts - including public schools and immersion language learning programs - bilingual children learn appropriate language and behavior through repetitive activities and routines. Willett (1995) illustrated how the participation of four ESL students in interactional routines in a mainstream first grade classroom led them to construct not only communicative competence, but also social relations and identities. Interactional routines are fixed and predictable sequences of exchanges that facilitate the learners’ ready participation (Peters and Boggs 1986; Willett 1995). Kanagy (1999) demonstrated how children in a Japanese immersion class autonomously became socialized through participating in the three routine activities - greeting, attendance taking, and the personal interview. Children learn how to answer and how to participate by repeatedly participating in a predictable sequence. Furthermore, children and novices can become active and self-regulating as they develop familiarity with the routine (Moore 2012).

In addition to interactional routines, peer cooperation helps students gain competence in the formal educational context. In Willett (1995), three girls taking ESL in particular demonstrated language and academic development through participation in the phonics class's routines and mutual collaboration. Although the teacher said 'do your own work,' students knew that they could talk to and help one another. Peer interaction and cooperation contributes considerably to children's socialization in the classroom. In Toohey (1998), certain individual practices in the classroom, such as sitting at one’s own desk, using one's own things, and using one’s own words and ideas, impeded participation and development of students who take ESL. 
Toohey (1998) argues noncollaborative classroom environments can have detrimental effects on the language development and socialization of children who take ESL.

In the Japanese immersion kindergarten classroom that Kanagy (1999) observed, teacher scaffolding and peer collaboration played a major role in children's participation in the routine activities. Through the teacher's explicit and implicit modeling, signaling, scaffolding, praising, and corrective feedback as well as peer modeling and cooperation, students acquired second language competence in the form, content, and participant structure. Duff $(1995,2004)$ and her students (e.g., Kobayashi 2003; Morita and Kobayashi 2008) examined language socialization in academic discourse in bi- and multilingual contexts. They mostly focused on secondary and postsecondary students' oral presentations and in-class and online discussions. A limited number of studies have demonstrated that student cooperation and participation in routine activities facilitated bilingual students' adherence to their school's rules and programs. More detailed examples and descriptions of socialization of young bilingual children in formal scholastic contexts remain necessary.

\section{Bilingual children, language, and socialization in informal educational contexts}

While some instructional approaches in informal educational contexts including heritage language schools and religious settings are similar to those in a formal school (e.g., repetition), the interactional characteristics and socialization process in informal educational contexts are flexible and multidirectional, and their educational goals are to construct ethnic and religious identities in addition to building knowledge and skills (Fader 2006; He 2000; Lo 2009). In Lo (2009), teachers and students in a Korean- American heritage language school displayed flexibility in negotiating their beliefs and practice: children showed their own agency and did not always obey the teachers, and teachers reworked their language ideologies based on the 
children's practices. The classification of student behavior and teacher response as respectful or disrespectful emphasized the local context over national culture and thus followed specifically Korean- American expectations rather than typical South Korean behavioral norms. In He (2000), which examined teachers' directives that contained cultural information and engaged students' participation in Chinese heritage language school classrooms, students cooperatively constructed teachers' directives and even challenged a teacher to modify her strategies. Both Lo (2009) and He (2000) suggest that novices' socialization is assisted and encouraged, but not determined by cultural and social authority figures or features as Ochs and Schieffelin (2012) explain.

In classes of informal educational institutions, such as heritage language schools or religious settings, teachers - volunteers in many cases - often use the target language as well as the students' dominant language to promote students' learning and meet their needs and allow bilingual students to use two languages (Al-Azami et al. 2010). Such a learning environment fosters close and friendly teacher-student relationships (Kenner and Ruby 2012). Also, as the classes are often mixed-level or mixed-age, older students can play the role of expert, knowledgeable peer, or mediator (Rosowsky 2006).

As the studies reviewed demonstrated, in informal educational settings salient features of teacher-student interactions include flexibility, informality, and negotiation. Furthermore, bilingual students in the heritage language school or religious educational setting explore both their multicultural identities and learner identities (Creese et al. 2006). In formal education contexts, bilingual students find limited opportunities to explore and display their bilingual identities, as they learn and follow the rules and norms in one language. Informal learning 
contexts, in contrast, provide bilingual children with spaces and chances to construct their bilingual identities and competences in a relaxed and unrestrained environment.

\section{Bilingual children, language, and socialization in both formal and informal educational} contexts

There are researchers who have examined multilingual children's socialization processes and/or learning experiences in both formal and informal educational settings. García- Sánchez (2010) followed six immigrant Moroccan students to an Arabic class at a public school and an Arabic after-school religious school at a local mosque to investigate the similarities and differences between the two Arabic educational settings. The study found that although repetition and recitation as a pedagogical approach were similar in both settings, the schools emphasized different aspects of the language: the public school's Arabic class valued standard Arabic associated with literacy, political importance, and global communication, and stressed learning the lexico-semantic meanings of linguistic forms. The mosque’s class considered the correct reproduction of pronunciation crucial to learning Arabic and sought to reinforce the children’s ethnic and religious identities. While demonstrating how immigrant children would be socialized in contexts where language and culture are entwined, García-Sánchez (2010) maintains the value of investigating language socialization practices across contexts because it helps understand ‘immigrant children’s affordances, and constraints in developing a hybrid, yet coherent, sense of identity across the sometimes similar, but often incongruous, communities and settings that they have to navigate on a daily basis’ (193).

Employing language socialization theory, Moore (2006) examined similarities and differences of instructional practices between a Qur'anic and a public school in Cameroon. Moore (2006) was looking to understand how the learning practices contributed to Fulbe 
children’s development of linguistic and cultural competence. Similar to García-Sánchez (2010), Moore (2006) found that the common activity in both the Qur'anic and public schools was repetition, more specifically ‘guided repetition’ (115). Yet clear differences between the two schools existed; in a public school classroom, for example, any student could model texts, but in the Qur'anic school only designated competent students had the authority to model a Qur'anic text and monitor and correct other students. The public school mainly tried to motivate students with play, praise, and competition, though these were infrequent in the Qur'anic school. These differences demonstrate the unique learning environment of each context.

The Qur'anic school taught Qur’anic texts and helped students obtain religious knowledge, so the students were socialized to faith in God and respect for authority and social hierarchy as a process of becoming a Fulbe and a Muslim. Students in the public schools were expected to have linguistic competence in French in an environment that valued learning from peers and encouraged a playful and relaxed atmosphere. Moore (2006) can shed light on academic socialization in at least two ways. First, instructional and interactional practices and students' socialization processes are impacted by the learning content and goals of a learning context, not necessarily by the formality of schooling (e.g., public school vs. community-based school). Second, children develop linguistic and cultural competencies and construct multiple identities by participating in both formal and informal educational settings.

Kenner (2004) followed young children at their primary school and heritage language school. He drew on Stuart Hall's perspective that an individual is conceptualized as multiple selves and identities in relation to the multiple social worlds he or she inhabits. In doing so, Kenner (2004) illustrated that bilingual children experience two connected - rather than separate - linguistic and cultural worlds. While children were able to differentiate between the two 
writing systems of English and their heritage language, they expressed simultaneity and connections between those two systems. The one year observation of the children both at their primary school and heritage language school enabled Kenner to discuss how bilingual children integrated and synthesized their literacy resources.

Studies that have focused on children's socialization in either formal or informal contexts demonstrated particular instructional practices, discourses, and ideologies in each educational setting. In contrast, research that has followed children in both formal and informal settings has offered insight into not only specific characteristics of each educational context but also children's learning and socialization through multiple forms of interactions and environments.

\section{Methods}

\section{The focal child}

The focal child of the study, Meeso (all the names are pseudonyms), is a Korean- American girl who was born and raised in the USA. She was seven years old and in first grade when the study began. Her parents are Korean and they immigrated to the USA three years before Meeso was born. Meeso goes to a public elementary school where only English is used. Her success on an English test allowed her to forgo ESL classes.

Based on academic reports and teacher interviews, her academic performance in first grade is above average. She belongs to the highest reading level group and she actively participates in class activities. According to Meeso's teacher in first grade:

Meeso is reading above the first grade level. I've seen her reading, how extensive and how good she is and her understanding of what she reads. She does participate in everything. She always usually has a good answer. Her drawing is exceptional. However, she's a little bit of a perfectionist. She can't finish something in an amount of time because of the details she's putting into it. 
The assistant teacher who leads Meeso's reading group assessed Meeso as a highperforming student. When Meeso seemed unable to concentrate in the class, the assistant teacher explained, 'That's why I sent her to the nurse. She doesn't seem to be herself.' Because the assistant teacher commonly saw Meeso participating actively and working hard, the teacher concluded that Meeso's unusual behavior might indicate her student does not feel well. Meeso's art teacher praised her artistic skills, and noted ‘She’s got great skills, craftsmanship. She really does a fantastic job.' However, the art teacher further commented that in the beginning of the semester Meeso rarely completed her assigned art projects on time. She attributed this problem to Meeso's meticulous, detailed approach to drawing, and the teacher added that Meeso gradually improved in this respect.

Meeso usually speaks Korean in conversations with her parents and sister at home, while she mostly speaks English with her Korean-American friends at church and friends at school. Whether they were born and raised in the States or moved to the States as young children, all her friends from church (affiliated with a Korean community in the USA) take the ESL class. During an interview Mary, Meeso's Sunday schoolteacher, explained that she thought Meeso had been taking the ESL class as well and that she regarded Meeso's English proficiency as similar to or below Meeso's church peers'. Moreover, Mary stated during the interview, 'I notice she really doesn't want to do like crossword, puzzle things [literacy-based activities]. I notice she really wants to draw a lot and she spends a lot of time on coloring and drawing.' An adult Sunday school volunteer also noticed that Meeso worked more slowly than her peers. Meeso’s Korean proficiency is low overall; Meeso speaks Korean with pauses and stutters and she makes constant pronunciation and grammar mistakes. But her speaking and listening abilities are better than her reading and writing abilities; Meeso has repeatedly learned Korean alphabet, Hangul and 
practiced reading and writing basic vocabulary (e.g., desk, chair, duck, bear) in her Korean heritage school.

\section{Sites}

Intercultural Elementary School (IES), where Meeso attended first grade, is the only school that has ESL programs in its district. IES’s school district emphasizes specific core values - respect, responsibility, and readiness - to their students. Students at IES pledge every morning to be ready to learn each day, to respect everyone and everything, to be safe, to be caring, and to make good choices. Meeso’s first grade teacher, Mrs Madison, is an experienced teacher with over 15 years of kindergarten and first grade teaching experience.

Meeso’s Korean-American church offers children’s services, Sunday school, and Korean language school for children. The majority of the children have immigrant parents and were born in the USA or moved to the USA at an early age. The children are divided into two age groups for Sunday school and Korean language school: an early childhood group (2-5 years old) and an elementary group (6-12 years old). Children in the elementary group predominantly use English. The elementary group’s Sunday schoolteacher, Mary, is a bilingual Korean-American. Mary speaks mainly English with the students in the elementary group. A church member and volunteer Sunday schoolteacher, Mary, has known many of the children in her class since they were babies, including Meeso.

\section{Data collection and analysis}

For the year from December 2010 to December 2011 and through 58 visits to the two sites, I video- or audio-recorded approximately 120 hours of classroom activity. I visited the public elementary school 30 times (24 visits in the spring semester and 6 in the fall). I visited the church 26 times (18 visits in the spring and 8 in the fall). During the spring semester, I observed the 
child at each site at weekly intervals and occasionally twice per week; during the fall, I visited each site once or twice a month.

The unit of analysis is a 'communicative event' or a 'speech event' (Hymes 1974; Saville-Troike 2003). A continuation of the same topic among the same participants in the same setting defines a single event. A total of 360 contextual, interactional, and interview events were analyzed. I divided my data into two broad types based on whether it was collected through observation or interview. That collected by observation was further divided into interactional and contextual. By distinguishing contextual from interactional data, I intended to identify the specific environmental characteristics of each context and to focus on the child's socialization through interactions in which she was the major interlocutor. Interactional data include conversations and interactions in which the focal child was engaged as an interlocutor. For interactional data, I identified both teacher and student conversation patterns that related to academic performance and socialization. Contextual data give information about the particular academic context (e.g., classroom procedures, values, rules, etc.) and in which the teachers were mainly speaking to the whole class and the focal child behaved as a quiet audience, or rule follower, rather than a direct interlocutor. I interviewed Meeso, her teachers, and her peers. Table 1 shows the amount of contextual, interactional, and interview data obtained from the public school and the church’s Sunday school, respectively.

During open coding, I identified descriptive descriptors - such as date, place, people, topic, manner of speech, language, and artifact - as well as inferential descriptors - such as emotion, role, goal, and outcome in each communicative event. While looking for patterns and analytical insights in Meeso's interactions with her peers and teachers in both contexts, I grouped similar events together and focused on recurring events. I counted the number of events to find 
the frequency and proportion of all events observed and then selected recurring and representative interactional events from the database (Corbin and Strauss 2008; Dyson and Genishi 2005).

\section{Findings}

\section{School: explicitness, repetition, and cooperation}

I will start by describing a typical writing session in Meeso’s first grade classroom to demonstrate several different interactional dynamics such as the teacher's lecture, teacherstudent interactions, and peer interactions at the same time. By demonstrating different interactional dynamics in which Meeso was involved, I intended to show the particular classroom context that afforded diverse opportunities for socialization. Then I will examine teacher and student discourses including Meeso's to determine the major factors that could contribute to Meeso and her classmates' socialization. A typical writing session in the school would start with the teacher's lecture concerning the day’s topic (e.g., a book the class has read, a field trip, or free writing). The teacher, Mrs Madison, would explain and exemplify in detail how to begin (e.g., 'one day,' 'one time,' 'once upon a time'), how to spell confusing words (e.g., 'they' instead of 'thay'), how to connect sentences, and how to outline using a graphic

Table 1. Number of communicative events with teachers and peers.

\begin{tabular}{llcrr}
\hline Context & Type & Teachers & Peers & Total \\
\hline Public school & Contextual & 75 & 3 & $78(35 \%)$ \\
& Interactional & 48 & 68 & $116(53 \%)$ \\
& Interview & 25 & 2 & $27(12 \%)$ \\
& Subtotal & 148 & 73 & 221 \\
Sunday school & Contextual & 34 & 4 & $38(27 \%)$ \\
& Interactional & 30 & 67 & $97(70 \%)$ \\
& Interview & 3 & 1 & $4(3 \%)$ \\
& Subtotal & 67 & 72 & 139 \\
\hline
\end{tabular}


organizer. After the lecture, students would be given 10 minutes for planning ('Quiet Ten'), during which soft and slow music would play. During Quiet Ten, students were generally prohibited from speaking loudly with each other, but those speaking softly to each other would frequently continue unpunished. Mrs Madison would thus allow students to talk softly with each other unless they made enough noise to interrupt other students or discussed something unrelated to the assignment. After about 10 minutes, Mrs Madison would let students know, 'Now Quiet Ten is done, so you can talk and ask for help. You can talk to your neighbor, but you are still working, ok?'

Mrs Madison and the other teachers were direct, clear, and explicit about the different behaviors and values they expected of their students. Table 2 summarizes three major patterns in the teacher-engaged contextual and interactional data in the public school; unusual patterns were not included. Teachers directly mentioned undesirable and unacceptable behaviors in 45 (37\%) out of 123 contextual and interactional events in which they engaged. Twenty events of these 45 events concerned social practices or norms (e.g., violating the school pledge, plagiarizing, cursing, bullying, interrupting, acting inappropriately). The students were expected to behave as directed and follow the school pledge as well as teachers' instructions and rules. Instead of simply telling a group of students who discussed spelling loudly to be quiet, Mrs Madison said, 'Green table. You need to start becoming independent and trying it by yourself.' Mrs Madison as well as the art teacher repeatedly warned students not to copy other students' ideas (e.g., 'Remember. Each one of you has your own idea. Please don’t copy the ideas from the person next to you'). When two students wrote about the same topic Mrs Madison rearranged their seating (e.g., 'You cannot sit next to each other. You're writing the same thing'). Furthermore, when Meeso was whining during the art teacher's demonstration, the art teacher immediately 
stopped and directed her: 'Stop whining.' The teachers corrected students' behaviors and reminded them of the class rules for 12 of the 45 events. Similar to Quiet Ten, there were rules for different contexts: a bus rule-'Use an inside voice and do not stand up'; a lunch rule-'Stay in your seat. Follow directions. Use inside voice. Clean up yourself'; and an art demonstration rule'No leaning, no touching, no talking.' And for 11 of the 45 events the teachers clearly discouraged certain poor writing practices (e.g., forgetting to indent, writing incomplete sentences, misspelling, and using vague concluding sentences such as 'It was fun' or 'I was happy').

Table 2. Major contextual and interactional patterns with teachers in the public school.

\begin{tabular}{lcr}
\hline School (Total 123 events) & No. of events & $\%$ \\
\hline Undesirable/unacceptable behaviors & 20 & \\
Norms/social practice & 12 & 16 \\
Rule & 11 & 9 \\
Learning & & 7 \\
Desirable behavior & 9 & 6 \\
Norms/social practice & 7 & \\
Learning & 5 & 4 \\
Procedural instructions & 17 & 14 \\
Norms/social practice & & \\
Learning &
\end{tabular}

Teachers clearly let the students know which behaviors were desirable and commendable in $16(13 \%)$ out of 123 teacher-involved contextual and interactional events. Mrs Madison encouraged students to be ready to learn and to be independent. As a way to teach those values and convince students, she frequently brought up the student pledge to instill learning attitudes in her students. A total 9 of the 16 events were related to social practices and norms (e.g., being ready to learn, following the teacher's rules and instructions, or being polite), while a total 7 of 
the 16 events were related to learning content (e.g., writing in detail, using an introduction and a conclusion, having good spacing, or using one of the story starters the teacher taught). Mrs Madison rewarded students by giving 'plus tickets' which could be traded in for books. She encouraged this reward system and exclaimed 'Awesome. Go get a plus ticket,' 'You look ready. Plus ticket,' and 'If you’ve finished your spider today, you may get a plus ticket.'

In addition, teachers constantly monitored students’ progress and let them know what they needed to do next in 22 of 123 teacher-engaged contextual and interactional events, indicating that time management is part of learning. Out of these 22 events, 17 concerned learning (e.g., 'Meeso, you are gonna have to start to trace soon.' 'Meeso, no more drawing. I want you to get in the outlining. It has to be done by the end of the class.' 'You've been writing for 20 minutes. You think two sentences good enough for two minutes?'). Meeso’s time management was a major concern expressed by her teachers during the interview, and the time management issue was apparent during my observation as well. Meeso spent too much time on detailed drawing and penmanship, so she frequently wrote fewer sentences than her peers. As the interview with Mrs Madison shows, Meeso had difficulty completing her work within the suggested time frame. In Meeso’s first grade classroom, children drew and wrote in assigned writing sessions. In the middle of the first semester, Mrs Madison told Meeso that she had to write, not draw first because Meeso had chosen to focus on drawing instead of writing. During the second semester, Mrs Madison often monitored Meeso’s writing progress and told Meeso to focus on the story (Excerpt 1). Mrs Madison monitored Meeso’s writing progress by checking how much Meeso had written, alerting Meeso to the possibility of not completing her work, checking what Meeso had written, and reminding Meeso that the quality of writing was more important than her calligraphy. 
(1) T: Mrs Madison, M: Meeso

T: Meeso, how many sentences?

M: Um ... one.

T: (Surprised) Huh? Meeso, read to me what you have.

M: [Reading unintelligibly].

T: Ok, you need to stop because I can't understand. [Coming over to Meeso] Try again.

M: One day a little girl was outside sledding with.

T: With who?

M: Her brother.

T: Ok, finish the sentence. Do you see all of this erasing?

M: [Nodding her head] Um um.

T: You are worried more about what your letters look like than you're worried about your story. I don't care what your letters look like right now. I care about how good your story is. Ok. So finish this sentence and get your next one.

Mrs Madison was well aware that Meeso paid more attention to her penmanship than to the content of her writing, so Mrs Madison constantly monitored Meeso's progress and helped her manage time. By the end of the first grade, though Meeso's time management still needed improvement, she had improved in pacing her writing with her classmates. Correspondingly, Mrs Madison's comments to Meeso during writing sessions later in the year addressed content more than time management issues (Excerpt 2). Increasingly, they talked about punctuation marks, ellipses, and narrative voice.

(2) T: Mrs Madison, M: Meeso

T: What do you use 'dot dot dot [...]' for?

M: Continue.

T. Ok, usually 'dot dot dot [...]' that ellipsis is a good thing when it's at the end of page, cos' you know there's nothing here but there is something else coming, right? Do you think we need it here?

M: No.

T: Why not?

M: Because it's actually at the end of page.

T: Yes, we don't really need that 'dot dot dot'. Now let me tell you. An ellipsis, 'dot dot dot,' is a very grown-up thing to do when you write. Did you know that?

M: No.

$\mathrm{T}$ : It is. The other thing I wanted to let you know is I'm noticing that you're starting to add voice to your writing. I can hear [emphasizing] 'you' when I read this. Right here, read that part.

M: [Reading her writing] 'Still, she didn't get a puppy for a Valentine.' 
T: This use of 'still,' that's adding voice. That's saying it in a unique way or a different way. It's very very good writing. I want you to keep thinking of different ways to write things. Ok? Because that means you're adding your voice to your writing. Sound good? [High five with Meeso] Nice job!

As described, the schoolteachers' effort to socialize the students was explicit, direct, repetitive, and even included individual reminders to students of their expected outcomes and attitudes so as to encourage them to regulate their own behavior. In addition to explicit, direct, and immediate instructions, Mrs Madison helped her students socialize by fostering an environment that encouraged her students to discuss issues among themselves with minimum interference.

Meeso and her peers encouraged each other's socialization by giving favorable and unfavorable comments in a total 31 (44\%) out of 71 total peer interactional and contextual events. Favorable comments (13 events, $18 \%$ of peer interactional and contextual events at school) included praise, personal attention to or concern for one's peer, and asking for help. Students, including Meeso, frequently asked for spelling help while writing (e.g., 'How do you spell 'bounce'?' 'How do you spell 'lost'?') and asked about each other's drawings (e.g., 'What's that on the face?' 'It's a mask'). Also, some students asked Meeso to draw (e.g., 'Can you draw me a castle?') and Meeso paid compliments to her peers (e.g., 'I like your first castle’).

Unfavorable comments (18 events, 25\% of peer interactional and contextual events at school) resulted from one’s peer having broken a rule (e.g., Quite Ten) or a norm (e.g., 'Don’t copy' and 'Wash your hands'). Some of the unfavorable comments that Meeso and her classmates exchanged were critical and demanding, however, those comments could be constructive and instructive socialization opportunities for their peers because the comments concerned the rules or values that the teachers emphasized to the class (Excerpt 3).

(3) M: Meeso, H: Hana (classmate) (Meeso and Hana were reading partners during buddy reading. Each was supposed to read a page and take turns.) 
M: [Reading the book] 'Then he saw it was Max. [A new page starts, but Meeso keeps reading] That was scary, said...'

H: No, I was supposed to do that. [Reading the book] 'That was scary, said Clapton.

Nothing scares me, Max said.'

M: Please can I do the whole story ... please?

H: No! That's not the way she [Mrs Madison] said.

$\mathrm{M}:$ Ok.

Overall, Meeso did not have difficulty following the teacher's stated rules of acceptable language and behavior in class. The environment fostered assignment-related conversations and mutual assistance among students and thereby facilitated socialization in the school.

\section{Church: implicitness, less structured environment, and diverse language attitudes}

The Sunday school in the church Meeso attended followed a schedule: Practice of children's hymns in Korean and in English, a children's religious service that included scripture reading, an interactive sermon, the offertory, prayers, and a worksheet session. The Sunday school's worksheet session was most similar to Meeso’s first grade class’s writing session, as students in both settings were supposed to work independently while sitting in a group. A typical worksheet session in the Sunday school began after the teacher had distributed a set of worksheets to each student. Each set covered one religious theme and consisted of several tasks including coloring, scrambled word games, crossword puzzles, maze, and reading comprehension questions. Except for coloring, all the tasks were strongly literacy-based and involved learning and practicing new vocabulary, problem solving, and reading. The teacher, Mary (students address the Sunday schoolteacher by her first name, unlike teachers in the public school), did not give any specific instructions, but the worksheets included straightforward instruction for each task. Students started with whichever part of the worksheet they preferred, worked independently, and occasionally discussed the work among themselves. Mary would complete the worksheet at the 
same table, help students who required assistance, and join or interrupt students’ conversations minimally.

There was no formal assessment for the work’s quality. Instead, work ethic and task completion were valued. For example, Meeso almost always started the worksheet by coloring since she enjoyed drawing and art projects. Meeso changed the figure’s outline and created a unique and notable work each time. Meanwhile, most other children started from the languagerelated activities, such as a scrambled word search or crossword puzzles. Unlike most of the girls in the Sunday school, the boys usually scribbled quickly on the coloring page and said 'I'm done.' Frequently Meeso did not complete the worksheets on time because she spent too much time coloring. Occasionally she even stayed behind and attempted to complete the worksheet when everybody else had gone upstairs for lunch. An adult church member who volunteered in the Sunday school told me she thought Meeso was a slow learner. Yet, when comparing the students’ coloring pages, the superior quality and effort involved in Meeso’s work was readily apparent. No teacher or volunteer, however, was attentive to the quality of the students' coloring.

Table 3 summarizes the major patterns of teacher-involved contextual and interactional data in the Sunday school; unusual patterns were not included. Out of 64 contextual and interactional events involving Sunday schoolteachers, 25 events (41\%) show that the overall atmosphere of the Sunday school was casual and lenient. Mary and her students had casual conversations and they sounded like friends. The students habitually created similar casual environments with other adult volunteers. When talking to Koreanspeaking volunteers in the Sunday school, Meeso rarely used honorific expressions or respectful speech. Due to the complexity of honorific speech styles in Korean, teaching it to children or Korean language learners is sometimes delayed, but non-honorific speech is considered impolite or casual in 
Korean (Brown 2013). That the Sunday school environment accepted Meeso’s non-honorific speech style of talking to teachers and elders in Korean demonstrates the Sunday school's casual, informal atmosphere.

The students’ refusal to follow Mary’s instructions and requests further demonstrates the Sunday school's casual and lenient atmosphere. When Mary told students to be quiet, students occasionally responded 'no,' and Mary also allowed students to discuss topics unrelated to the worksheet (e.g., TV shows or movies) while completing the assignment. Even when Mary tried to discipline students, students were not always compliant. For instance, when a boy made his worksheet appear finished by quickly circling and marking incorrect answers, Mary said 'That's warning one. Do it correctly.' The boy then completed the exercise incorrectly again and showed it to Mary with a joking smile. Mary said 'Warning two,' but nothing further. The boy did not seem to take the teacher's warnings seriously. Excerpt 4 also illustrates the Sunday school's atmosphere. Children sometimes received small prizes, and one such prize was a rubber toy that

Table 3. Major patterns of teacher-involved contextual and interactional data in the Sunday school.

Sunday school (total 64 events) No. of events $\quad \%$

Lenient and casual atmosphere

Casual environment 1828

Student refusal and resistance

6

Desirable behavior

Religious attitude

Undesirable behavior

Unsacred behaviors

Instruction

Religion 8

Discussion-based learning 
popped up when flipped. One week, Meeso repeatedly pled and whined that she wanted to have a pop-up after having seen one of her peers play with one. However, according to stated rules, Meeso had to collect more reward stickers to earn such a prize. Mary gave out two pop-ups - one to Meeso and one to another child - in response to Meeso's persistent pleas. A week later, Meeso repeatedly requested to exchange her green pop-up for a yellow one, and again began to whine and plea for her cause. This time Mary did not oblige her demands and instead refused Meeso a new pop-up.

(4) T: Sunday schoolteacher Mary, M: Meeso, Y: Yewon (peer) M: [Looking at Yewon playing with her pop-up] I wish I had a pop-up. [26 seconds later] I wish I had a pop-up. [8 second later] I wish I had a pop-up. [11 seconds later] I wish I could get a pup-up. [59 seconds later] I wish I could get a pop-up.

$\mathrm{T}$ : [Calling Meeso] Meeso, Meeso [taking Meeso outside].

M: I wish I could get a pop-up. [1 minute later, coming back to the classroom and holding two pop-ups] I got two pop-ups.

Y: Oh my god.

[Next week]

M: It doesn't work so well. I just don't like that pop-up. [37 seconds later] I don't like that pop-up. [25 seconds later] Mary, I don't like that.

Y: I want the yellow one too.

M: Mary, I don't like that.

$\mathrm{T}$ : You picked the green.

M: I know, but I wanna change my mind. I don't want anything except that yellow one.

Y: I want that too yellow one.

T: If you are gonna whine, Meeso, if you're not gonna share, then neither one of you get this. Nobody is gonna get this.

These events from consecutive weeks depict the teacher's inconsistent reactions to the similar behavior - whining for an unreasonable request - and the class' absence of fixed rules. Meeso was able to get a toy after her repeated request one week, but the same strategy did not work the next week.

Although no particular rule was emphasized in the Sunday school, religion-related behaviors and attitudes were addressed or corrected in 15 of the 64 events, or $20 \%$ of the contextual and interactional events between teachers and students in the Sunday school. Sunday 
schoolteachers clearly reminded students of plus (desirable and laudable) and minus (undesirable and punishable) behaviors related to student attitudes toward the religion and participation in religious services. The teachers judged adherence to religious values positively and irreligious behaviors and attitudes as undesirable, punishable offenses. Such judgments indicate that a religious attitude was the teachers' only expectation for the Sunday schoolchildren. The students received stickers for showing desirable attitudes, such as quietly preparing for the service and folding their hands to pray. Similarly, students lost stickers they had earned for bad behavior, such as not being ready for or chewing gum during the service. In the Sunday school, students had nothing resembling the lunch rules, demonstration rules, hallway rules, and do-not-copy policy of Meeso's elementary school. Although attitudes toward the religious service and religion were emphasized more than any other rules, the overall learning environment of the Sunday school was much less structured and constrained than that of the public school.

Peer interaction in the church both resembled and differed from that in the public school. Children in the Sunday school were similarly conscious about copying and not copying other students' ideas. They monitored and warned each other, saying 'Don't copy me' and 'Stop copying mine' in a total of 10 events (14\% of 71 peer interactional events in the Sunday school). Even though the Sunday schoolteacher never asked the students not to copy, the children autonomously prevented their peers from copying their work. This could show that children transferred the social knowledge they had acquired in elementary school to the Sunday school. Including the comments about not copying, Meeso and her Sunday school peers demonstrated unfavorable attitudes and directed antagonistic language toward each other (46 events, or $65 \%$ of 71 peer interactional events) much more often than Meeso's school classmates (18 events, or 25\% of 71 peer events) did. In fact, Meeso and her Sunday school peers exchanged favorable 
comments in only 9 out of 71 peer interactional events (13\%) which was lower, compared to interaction with her school classmates (13 events, or 18\% of 71 peer interactional events).

The proportion and the intended results of these unfavorable conversations distinguish the Sunday school peer interaction from public elementary school peer interaction. Whereas Meeso's school classmates gave unfavorable comments in order to socialize and teach their peers, Meeso’s Sunday school peers - mainly boys - showed unfavorable attitudes that could hurt Meeso’s feelings as shown in Excerpts 5 and 6. As in Excerpt 5, Jongho often remarked sarcastically upon Meeso’s drawings. The boy’s reactions to potential flaws in Meeso’s drawing did not demonstrate an intention to explicitly encourage Meeso toward certain value, norm, or rule. When she gave a princess she had drawn an incongruently oversized face and when she drew an out-of-fashion cartoon character, the negative remarks she received were neither constructive not helpful, but disrespectful and oppositional.

(5) M: Meeso, J: Jongho, boy peer

M: I wanna turn this into a girl. [Changing a boy to a girl on the coloring page] J: [Facing Meeso, saying sarcastically] Hey, you made a transgender. I don’t understand why you always make a transgender.

(6) M: Meeso, H: Han, boy peer Meeso: I wish we could be a little peaceful in here.

Han: Yeah, it could be peaceful if you are out of the classroom.

Interestingly, Meeso code-switched or mixed most while interacting with antagonistic peers, and especially when she was upset or uncomfortable with the situation. In Excerpt 7, a boy in the Sunday school disturbed Meeso by erasing her drawing on the whiteboard without asking. She tried to express herself but she was not very successful and rather than completing her sentence in English, she mixed Korean and English.

(7) Y: Yewon, M: Meeso, H: Han, J: Jongho Y: [Shouting] Oh my goodness! He's [Han] erasing it.

M: [Raising her voice] Oh, Han, I was gonna ... [after a short pause] Han! 
$\mathrm{H}$ : [Keeps erasing the drawing]

Y: [Raises her voice] Han, you're erasing her dress.

M: Ania, Ania, Na Ee Run Geo... 'No, no, I was like...' [3 sec pause] You just ruined it. [Sounds almost crying]

$\mathrm{J}$ : We should erase it whatever (because the Sunday school started).

The context gives a possible explanation for Meeso's code-switching: she might have been searching for an adult's help by switching to Korean as there were almost always Koreanspeaking adult volunteers in the Sunday school. Meeso consciously or unconsciously might have wanted to draw the interactant's attention by signaling her annoyance. Whether Meeso codemixed to express her emotion or to ask for help, codemixing and code-switching can be viewed differently according to the individual's linguistic ideologies, which will be discussed in the following section.

\section{Discussion and conclusion}

\section{Academic socialization in the monolingual, formal context}

This study has examined academic socialization in both formal and informal academic communities, by following a seven-year-old bilingual child in her elementary school and church Sunday school. The study has described in detail how, in the school context, a teacher's explicit instructions and peer collaboration helped Meeso and her peers socialize and supported Meeso improve her writing process. Research studying young bilingual children’s socialization in school has reported that routines help children socialize through participation in repetitive, predictable sequences (Kanagy 1999; Willett 1995). Building on previous findings, the present study has shown how highly explicit norms (e.g., independence and readiness to learn) and rules (e.g., bus rules, lunch rules, and art demonstration rules) facilitated both Meeso and her classroom peers' learning of and adherence to the school's expectations. In addition, the teacher's close attention, monitoring, and instructions had a noticeable impact on Meeso's 
writing efficiency and quality. My data show that the students grew more mature and independent by adhering to teachers' explicit expectations and corrections over time.

Crucial to my data was the children's active involvement in one another's socialization process. Toohey (1998) argues for the importance of peer interaction and communication for children's development and socialization in school. While Meeso and her peers helped one another when asked (for example, with spelling), as children have in previous studies, different forms of cooperation were also observed in my study. Children paid special attention to each other's work and ideas by asking questions and giving compliments. At the same time, children provided constructive comments that could sound commanding but were in fact intended to teach appropriate behaviors.

The teachers' explicit and repeated conveyance of norms and rules combined with peer cooperation made Meeso and her classmates’ socialization processes uncomplicated and manageable. As Meeso is proficient in English, socialization process may have been easier for her than for bilingual students whose English proficiency is low. However, since the school facilitated socialization exclusively in English, it never gave Meeso the chance to develop her bilingual and bicultural competences. The school curriculum and activities fail to utilize her bilingual and bicultural competencies as invaluable resources. Baquedano-López and Hernandez (2011) point out that the exclusive use of English for school practices and policies overlooks the academic advantages that a student's home language can offer. Hybridity and diversity can create transformative learning space (Gutiérrez, Baquedano-López, and Tejeda 1999). Thus each child's talents should be recognized and promoted within the school; educators should incorporate the linguistic, cultural, and intellectual resources that bilingual children bring from their homes (Cummins 2001). 


\section{Academic socialization in the informal, bilingual context}

This close, longitudinal observation offers a possible explanation for the teachers' contrasting evaluations of Meeso's learning and language abilities. The conclusion that Meeso is a slow learner could have arisen from the fact that the informal learning context did not include formal assessments and overstressed assignment completion. While her peers finished the assignments within the allotted time, Meeso put a great deal, and perhaps an excess, of her time and effort into the worksheet's coloring activity. Importantly, due to the absence of clear expectations and assessment, Meeso did not work on the literacy-based tasks as diligently as her peers. The less structured and more lenient atmosphere allowed the students more autonomy than in public school, but also allowed teasing and insults among classmates to go unchecked. Although Meeso’s malepeers in Sunday school sometimes might have hurt Meeso’s feelings, she did not appear to be bullied. Rather, according to the collected data and observed behavior, their friendships and feelings changed frequently so that the children frequently behaved like good friends in one moment but teased each other in the next.

On one hand, having few explicit rules and norms might have made the children's socialization difficult. Indeed, they were left to figure out the expected and appropriate behaviors and languages by a trial and error. And the teacher's inconsistent reaction to the children's behaviors might have confused them further. On the other hand, a limited number of rules could have given the students an opportunity to learn and enjoy an academic context with unpredictable and non-repetitive situations. In that sense, Meeso had the opportunity to experience diverse socialization processes because of her membership in multiple communities of practice. 
The evaluation of Meeso's language proficiency as poor in both languages can be explained by the evaluators' own language ideologies and language attitudes (Evaldsson 2005). Meeso's code-switching, code-mixing, or inconsistent use of the two languages might have contributed to some of the adult church members' perceptions that Meeso was proficient in neither English nor Korean, while all the other first graders in the Sunday school used English almost exclusively. In a multilingual context, members can have different language ideologies, or 'sets of beliefs about language articulated by the users as a rationalization or justification of perceived language structure and use’ (Silverstein 1979, 193). Whether learners' errors are corrected and how the errors and code-switching are viewed can be influenced by contextual norms and values (Friedman 2009; Moore 1999; Riley 2012). Language attitudes toward Korean-English bilingualism can vary depending on the background and situation of speakers (e.g., first and second generation Korean-Americans, Koreans temporarily residing in the USA, and Koreans residing in Korea). Koreans who were born and raised in Korea would consider perfect Korean proficiency a natural, common ability (Jeon 2001). Similarly, study-abroad student (jokiyuhaksaying) families in the USA believe 'Korean is a necessity and English is for survival' (Song 2010, 37). Korean immigrants' beliefs about Korean and English differ slightly from Korean sojourners. Although immigrant Korean parents generally want their children to be bilingual in Korean and English, they have mostly positive attitudes about their children using English at home and frequently believe English is necessary to live in the USA. (Shin 2005; Song 2010). Second generation immigrant families can have negative perceptions about people who speak only Korean, call them fresh off the boats, and believe that they will be rejected by American society (Jeon 2001). Ideally, both sojourners and immigrants prefer to have competence in both languages, but they believe at least one language should be full proficiency. 
For these populations, mixing two languages can be considered as a lack of fluency in either language. An increasing number of researchers view code-switching as a communicative strategy (Auer 1998; Gumperz 1982; Shin and Milroy 2000). In Shin (2010), it was considered appropriate that children in a Korean-American church switching from English to Korean to show deference to and address older people with respect. Still, some people view codeswitching as a strategy to compensate for language deficiency in either or both languages. Divergent language ideologies can result in divergent evaluations of a speaker's level of bilingual proficiency and use of code-switching.

\section{Nexus of multimembership}

This study has investigated the specific characteristics of each community in which the child socialized according to its distinct behavioral norms and rules as well as its members' attitudes and ideologies. While acknowledging that each community of practice holds its unique goals and values, I agree with Wenger (1998) that communities of practice are an 'integral part' of our lives (7). Having multiple memberships in linguistically and culturally different educational communities, bilingual children, such as Meeso, experience culturally and contextually distinct socialization processes. Educators, researchers, and parents should try to understand that bilingual children who engage in multiple communities combine their multiple memberships with their linguistically and culturally diverse experiences to construct their identities and develop their abilities: 'Our various forms of participation delineate pieces of a puzzle we put together rather than sharp boundaries between disconnected parts of ourselves' (Wenger 1998, 159). Meeso had two very different social and academic experiences and interactions. While she gradually became a competent member of the public school, her Sunday school socialization process developed rather slowly. Although the socialization process was slower and more 
ambiguous in the Sunday school, it is important to note that her experiences in both communities can help shape Meeso's identity and competence as a bilingual and bicultural child. Meeso's exceptional drawing ability and advanced reading ability at her public school could be due in part to her practice in the Sunday school. Perhaps Meeso’s immature social skills, such as whining, which were curtailed at the public school, were transferred from her experience in Sunday school; her whining received attention and got her something she wanted in Sunday school, where this manner of address was often tolerated. However, the two conflicting processes may not always merge in one particular moment or in one particular place, but into Meeso herself. In other words, the socialization processes Meeso experienced as a member of two linguistically, culturally, and functionally different academic communities could have a continual impact on her life as a multilingual and multicultural individual.

A critical part of helping bilingual and bicultural children grow as individuals who possess strong multilingual and multicultural competences is the joint effort of parents and teachers in both formal and informal educational communities. Teachers' observations and assessments of a student are mainly based on that child's performance in one context. They should not assume that children behave the same way in other contexts, where norms and rules might differ. Through a communication and partnership, teachers should deepen their understanding of their students and discuss any irregularities or contrasting evaluations among themselves. To that end, the parent's role is crucial. Parents of bilingual children should pay attention to their children's academic experiences in both formal and informal academic contexts. The parents should try to invest time and effort into understanding their children's academic experiences and provide any necessary support. This way the children can effectively 
discern different academic contexts and integrate the diverse experience to form their identity and competence.

The examination and promotion of differences in bilingual and bicultural children's social interactions and experiences in linguistically, culturally, and functionally different communities could enhance our understanding of the development of the child's perspectives and competences. Meeso's case - a strong student at school and a slow learner in the heritage language community - may be unique. In fact, the reverse case - performing poorly at school but performing well outside school - seems more prevalent (e.g., Li 2004; McMillon and Edwards 2000). In either case, children with multimembership experience similar and dissimilar socialization across diverse communities and these experiences have a vital impact on the child's growth and development because bilingual and bicultural children develop two separate, but connected languages and social norms.

\section{Acknowledgments}

The study was prepared from my doctoral dissertation and would not have been possible without the support of Janina Brutt-Griffler, X. Christine Wang, and Erin Kearney. I am grateful to anonymous International Journal of Bilingual Education and Bilingualism reviewers for their insightful comments and suggestions on previous drafts. 


\section{References}

Al-Azami, S., C. Kenner, M. Ruby, and E. Gregory. 2010. “Transliteration as a Bridge to Learning for Bilingual Education.” International Journal of Bilingual Education and Bilingualism 13 (6): 683-700. doi:10.1080/13670050903406335.

Atkinson, D. 2003. “Language Socialization and Dys-socialization in a South Indian College.” In Language Socialization in Bilingual and Multilingual Societies, edited by R. Bayley and S.R. Schecter, 147-162. Clevedon: Multilingual Matters.

Auer, P. 1998. Code-switching in Conversation: Language, Interaction and Identity. New York: Routledge.

Baquedano-López, P., and S. J. Hernandez. 2011. “Language Socialization across Educational Settings.” In A Companion to the Anthropology of Education, edited by B. A. U. Levinson and M. Pollock, 197-211. Malden, MA: Wiley-Blackwell.

Brown, L. 2013. “Teaching 'Casual’ and/or 'Impolite’ Language through Multimedia: The Case of Non-honorific panmal Speech Styles in Korean.” Language, Culture and Curriculum 26 (1): 1-18. doi:10.1080/07908318.2012.745551.

Corbin, J., and A. Strauss. 2008. Basics of Qualitative Research: Techniques to Developing Grounded Theory. 3rd ed. Los Angeles, CA: Sage.

Creese, A., A. Bhatt, N. Bhojani, and P. Martin. 2006. “Multicultural, Heritage and Learner Identities in Complementary Schools.” Language and Education 20 (1): 23-43. doi:10.1080/09500780608668708.

Cummins, J. 2001. “Bilingual Children’s Mother Tongue: Why Is It Important for Education?” Sprogforum 7 (19): 15-20.

Duff, P. A. 1995. “An Ethnography of Communication in Immersion Classrooms in Hungary.” TESOL Quarterly 29 (3): 505-537. doi:10.2307/3588073.

Duff, P. A. 2004. “Intertextuality and Hybrid Discourses: The Infusion of Pop Culture in Educational Discourse.” Linguistics and Education 14: 231-176. 
Dyson, A. H., and C. Genishi. 2005. On the Case: Approaches to Language and Literacy Research. New York: Teachers College Press.

Evaldsson, A.-C. 2005. "Staging Insults and Mobilizing Categorizations in a Multiethnic Peer Group. Discourse \& Society 16 (6): 763-786. doi:10.1177/0957926505056663.

Fader, A. 2006. “Learning Faith: Language Socialization in a Community of Hasidic Jews.” Language in Society 35 (02): 205-229. doi:10.1017/S004740450606009X.

Friedman, D. A. 2009. “Speaking Correctly: Error Correction as a Language Socialization Practice in a Ukrainian Classroom.” Applied Linguistics 31 (3): 346-367. doi:10.1093/applin/amp037.

García-Sánchez, I. 2010. “The Politics of Arabic Language Education: Moroccan Immigrant Children's Language Socialization into Ethnic and Religious Identities.” Linguistics and Education 21: 171-196.

Gumperz, J. J. 1982. Discourse Strategies. Cambridge: Cambridge University Press.

Gutiérrez, K., P. Baquedano-López, and C. Tejeda. 1999. "Rethinking Diversity: Hybridity and Hybrid Language Practices in the Third Space.” Mind, Culture, \& Activity: An International Journal 6 (4): 286-303.

He, A. W. 2000. “The Grammatical and Interactional Organization of Teacher’s Directives: Implications for Socialization of Chinese American Children.” Linguistics and Education 11 (2): 119-140. doi:10.1016/S0898-5898(00)00025-5.

Hymes, D. 1974. Foundations of Sociolinguistics: An Ethnographic Approach. Philadelphia, PA: University of Pennsylvania Press.

Jeon, M. 2001. “Avoiding FOBs: An Account of a Journey.” Working Papers in Educational Linguistics 17 (1-2): 83-106.

Kanagy, R. 1999. "Interactional Routine as a Mechanism for L2 Acquisition and Socialization in an Immersion Context.” Journal of Pragmatics 31 (11): 1467-1492. doi:10.1016/S03782166(98)00113-1. 
Kenner, C. 2004. “Living in Simultaneous Worlds: Difference and Integration in Bilingual Scriptlearning.” Bilingual Education and Bilingualism 7 (1): 43-61. doi:10.1080/13670050408667800.

Kenner, C., and M. Ruby. 2012. “Co-constructing Bilingual Learning: An Equal Exchange of Strategies between Complementary and Mainstream Teachers.” Language and Education 26 (6): 517-535. doi:10.1080/09500782.2012.666248.

Kobayashi, M. 2003. “The Role of Peer Support in Students’ Accomplishment of Oral Academic Tasks.” Canadian Modern Language Review 59 (3): 337-369. doi:10.3138/cmlr.59.3.337.

Li, G. 2004. "Perspectives on Struggling English Language Learners: Case Studies of Two Chinese-Canadian Children.” Journal of Literacy Research 36 (1): 31-72. doi:10.1207/s15548430jlr3601_3.

Lo, A. 2009. "Lessons about Respect and Affect in a Korean Heritage Language School.” Linguistics and Education 20 (3): 217-234. doi:10.1016/j.linged.2009.07.002.

McMillon, G. T., and P. A. Edwards. 2000. "Why Does Joshua "Hate” School ... but Love Sunday School?” Language Arts 78 (2): 111-120.

Moore, L. 1999. “Language Socialization Research and French Language Education in Africa: A Cameroonian Case Study.” Canadian Modern Language Review 56 (2): 329-350. doi:10.3138/cmlr.56.2.329.

Moore, L. C. 2006. “Learning by Heart in Public and Qur’anic Schools in Maroua, Cameroon.” Social Analysis: The International Journal of Cultural and Social Practice 50 (3): 109_ 126.

Moore, L. 2012. “Language Socialization and Repetition.” In The Handbook of Language Socialization, edited by A. Duranti, E. Ochs, and B.B. Schieffelin, 209-226. West Sussex: Blackwell.

Morita, N. 2009. “Language, Culture, Gender, and Academic Socialization.” Language and Education 23 (5): 443-460. doi:10.1080/09500780902752081. 
Morita, N., and M. Kobayashi. 2008. “Academic Discourse Socialization in a Second Language.” In Encyclopedia of Language and Education, Vol. 8: Language Socialization, edited by P.A. Duff and N.H. Hornberger, 243-256. New York: Springer.

Ochs, E., and B. B. Schieffelin. 1984. "Language Acquisition and Socialization: Three Developmental Stories and their Implication.” In Culture Theory: Essays on Mind, Self, and Emotion, edited by R.A. Shweder and R.A. LeVine, 276-320. Cambridge: Cambridge University Press.

Ochs, E., and B. B. Schieffelin. 2012. “The Theory of Language Socialization.” In The Handbook of Language Socialization, edited by A. Duranti, E. Ochs, and B.B. Schieffelin, 1-21. West Sussex: Blackwell.

Peters, A. M., and S. Boggs. 1986. "Interactional Routines as Cultural Influences upon Language Acquisition.” In Language Socialization Across Cultures, edited by B.Schieffelin and E. Ochs, 80-96. New York: Cambridge University Press.

Pon, G., T.Goldstein, and S. R. Schecter. 2003. "Interrupted by Silences: The Contemporary Education of Hong-Kong-born Chinese Canadians.” In Language Socialization in Bilingual and Multilingual Societies, edited by R. Bayley and S.R. Schecter, 114-127. Clevedon: Multilingual Matters.

Riley, K. C. 2012. “Language Socialization and Language Ideologies.” In The Handbook of Language Socialization, edited by A. Duranti, E. Ochs, and B.B. Schieffelin, 493-513. West Sussex: Blackwell.

Rosowsky, A. 2006. “' I Used to Copy What the Teachers at School Would Do’. Cross-cultural Fusion: The Role of Older Children in Community Literacy Practices.” Language and Education 20 (6): 529-542. doi:10.2167/le661.0.

Saville-Troike, M. 2003. The Ethnography of Communication. 3rd ed. Oxford: Blackwell. Scheerens, J., ed. 2006. Informal Learning of Active Citizenship at School. An International Comparative Study in Seven European Countries. Dordrecht: Springer.

Shin, S. 2005. Developing in Two Languages: Korean Children in America. Buffalo, NY: Multilingual Matters. 
Shin, S. 2010. “The Functions of Code-switching in a Korean Sunday School.” Heritage Language Journal 7 (1): 91-115.

Shin, S. J., and L. Milroy. 2000. "Conversational Codeswitching among Korean-English Bilingual Children.” International journal of Bilingualism 4 (3): 351-383. doi:10.1177/13670069000040030401.

Silverstein, M. 1979. "Language Structure and Linguistic Ideology.” In The Elements: A Parasession on Linguistic Units and Levels, edited by R. Clyne, W. Hanks, and C. Hofbauer, 193-247. Chicago: Chicago Linguistic Society.

Song, J. 2010. "Language Ideology and Identity in Transnational Space: Globalization, Migration, and Bilingualism among Korean Families in the USA.” International Journal of Bilingual Education and Bilingualism 13 (1): 23-42. doi:10.1080/13670050902748778.

Toohey, K. 1998. ““ Breaking Them Up, Taking Them Away’: ESL Students in Grade 1.” TESOL Quarterly 32 (1): 61-84. doi:10.2307/3587902.

Wenger, E. 1998. Communities of Practice: Learning, Meaning, and Identity. New York: Cambridge University Press.

Willett, J. 1995. "Becoming First Graders in an L2: An Ethnographic Study of L2 Socialization.” TESOL Quarterly 29 (3): 473-503. doi:10.2307/3588072. 